\title{
"Attitudes of Business Students Towards Career In Central Bank, Private Commercial Banks \& Nationalized Commercial Banks; A Study on Bangladesh"
}

\author{
Arifuzzaman Khan \\ MBA Candidate, Institute of Business Administration, University of Dhaka. Bangladesh \\ Sandip Sarker \\ MBA candidate, Management \& Business Administration School, Khulna University, \\ Khulna-9208, Bangladesh.
}

\begin{abstract}
:
The banking industry is always a major job provider in Bangladesh. Particularly, the expansion of private banking business, along with nationalized commercial ones, has created huge number of job opportunities. Different types of banks have different types of jobs. The job in the central bank (Bangladesh bank-BB) is different from any other commercial banks. It includes the strategic decision making for private banks and non bank financial institutions, monitoring and supervising them etc and thus it seems to be a prestigious job to the employees, though the salary structure is not very attractive. On the other hand two types of commercial banks are there, NCBs (nationalized commercial banks) and PCBs (private commercial banks). The NCBs and PCBs are doing the same commercial banking though the organizational structure and the job they provide are little different in character. But their attitude towards the entire banking career is off course not the same. Branding the job is another issue. "Employer branding" is relatively new and interesting topic. Here the human resources and the employment itself are branded. The Bangladeshi banks, except very private banks, are not practicing this concept. The study finds that the overall performances of PCBs are best followed by BB \& NCBs. That means to be branded as a good employer the government sector banks has to go through a major reformation process. According to the study 'Performance based promotion system' is found to be the most important attribute, followed by 'Remuneration', 'Growth opportunity', 'Social status', 'Job security' \& 'Brand image' and so forth. So based on those factors, to be considered as the best employer, all those banks have scopes for development.
\end{abstract}

Key Words: Attitudes, Employer branding, banking career.

\section{Background of The Study:}

The economy of Bangladesh has been experiencing a significant growth of nearly $6 \%$ over the past few years. This is especially in the manufacturing and service sectors. Recently govt. has approved nine banks in Bangladesh. Therefore competition has increased. At the same time it has created many job opportunities in the country. Banking sector is one of the major job providers of Bangladesh. Different types of banks have different types of jobs. Basically the major banking job can be divided into very few categories like the central bank job, the private commercial banks job and the nationalized commercial banks job. In Bangladesh HR branding or employer branding is a new concept. A few multinationals, Unilever, British American Tobacco, and Nestle 
are practicing this concept. They are arranging different programs to promote their Job as the best. Such kinds of initiatives include arranging different types of competitions, some media attention to their events etc. In the banking sector in Bangladesh, the concept is even newer. Some of the banks, only at the time of their recruitment, use some media to communicate with the potential buyers (employment seekers). Some banks, on their advertisements for jobs, include the salary and other benefits. This practice is even lower in the govt. owned banks. They generally don't do this kind of things. So in this research I tried to consider these jobs as the product and tried to understand the consumers (potential job seekers) attitude.

\section{Objective of The Study:}

The objective of the study is to recognize the factors for job selection specially for business students.

\section{Sub-Objectives:}

$\checkmark$ Determining the importance of each attribute of these three categories of banks.

$\checkmark$ Categorizing important attributes of a job which develops students' attitude.

$\checkmark$ Identifying the comparative position of these banks in the banking industry.

$\checkmark$ Measuring problems \& identifying probable solution in gaining positive potential job seekers' attitude

\section{Methods and Materials \\ Sources of data: \\ Primary Sources:}

The direct interaction with students through survey was the primary source to collect data. To collect data the students were interviewed personally. There was a primary survey and a final survey.

\section{Secondary Sources}

As secondary source, journals, books and reports were used related to students' attitude which couldn't be collected from primary sources.

\section{Research Question:}

With the help of existing literature and also evaluating the contexts of present set-up research questions have been determined. While setting the research question the future contribution of our research study has been considered. The research question is set as:

- Research Question: What factors are responsible for creating different types of attitudes among the business students in Bangladesh to choose their career in banking sector? 


\section{Research Design:}

In order to solve the above mentioned research question and this study has been adopted the following research design comprising data collection and analysis. This study has utilized survey research methodology. A highly structured questionnaire was developed based on discussions with selected university faculty, banking professionals and literature review. The pre-test was conducted by trained graduate students for wording, layout, content validity, and determining main data collection methods. They were provided with adequate training before taking their part in the research campaign. Those training have given them necessary idea about the questionnaire and also how to conduct an interview with questionnaire with different tour operators.

\section{Questionnaire:}

The questionnaire has been prepared in the light of the multiattribute fishbein model. Questionnaire was divided into two parts. First part consists of general information about the respondents. And the second part is about attributes of the banking services which reflect customer's attitude. Twenty (21) attributes e.g. Performance based promotion system, Remuneration, Growth opportunity, Social status, Job security, Brand image etc was selected from the pilot survey. At first, we went to the respondents and asked them to rank the attributes' importance as weighted from strongly disagree to strongly agree (numerically ranging from 1 to 5). Then the respondents were asked to rank their beliefs towards different brands regarding those attributes respectively. The ranking was ranging from strongly disbelieve to strongly believe (numerically ranging from 1=strongly disbelieve, 2=disbelieve, 3=neutral, 4=believe and $5=$ strongly believe).

Sampling: Convenience sampling method, a non-probability sampling technique, is used for the selection of sample.

\section{Target population \& Sample Size:}

The target population is the business students who are studying in different public and private universities of Bangladesh. Total 100 students were selected as sample. Among them

\section{Model}

A multiattribute attitude model was used for this purpose. Plenty of marketing research has been done on developing models to identify the attitudes produced by this integration process. Martin Fishbeins' model (1972) has been most prominent in marketing. The model says that, consumers have strong beliefs about specific brand attributes and different levels of importance are attached to these attributes. The fishbein model may be formulated as below:

$$
A_{\bar{B}}=\sum_{i=1}^{n}\left(B_{\mathrm{i}} E_{\mathrm{i}}\right)
$$

Where:

$$
\begin{aligned}
& A_{B}=\text { Attribute towards the object } \\
& B_{\mathrm{i}}=\text { Strength of the belief that the object has attribute, }
\end{aligned}
$$




$$
\begin{aligned}
& E_{\mathrm{i}}=\text { Evaluation of attribute } \\
& \mathrm{n}=\text { Number of salient beliefs or attributes about the object }
\end{aligned}
$$

This model, however, does not state that consumers actually add up the products of belief strength and evaluation when forming attitudes towards object. Rather, this and similar models attempt to predict the attitude produced by the integration process; they are not meant to describe the actual cognitive operations by which knowledge is integrated.

There are two major element of Fishbien's model-

$\checkmark$ Belief strength $\left(B_{i}\right)$, which is the apparent probability of relationship between an object and its relevant attributes.

$\checkmark$ Belief evaluation $\left(E_{\mathrm{i}}\right)$, that reflects how favorably the consumer perceives that attribute.

\section{Literature Review:}

(Barrow \& Mosley, 1990) first used the term "Employer Branding” in the 1990's in order to symbolize the organization as an employer. After that global management community adopted this terminology in practice. We can define employer brand as "the image of your organization as a 'great place to work' in the mind of present employees and key stakeholders in the external market. Therefore the art and science of employer branding is concerned with the attraction, engagement and retention of initiatives targeted at enhancing your company's employer brand." (Minchington, 2010). Like a customer brand proposition is used to define a product or service offer, an employer brand proposition is used to define an organization's employment offerings. Similarly the marketing disciplines that are closely connected with branding and brand management have been increasingly applied by the HR and talent hunting community to attract, engage and retain talented candidates, like the way the marketing uses such tools to attract clients, customers and consumers. Though the term 'employer branding' denotes association between organization and employees, employer branding has been defined as the sum of total of company's efforts to communicate to qualified and prospective staff what makes it a perfect place to work, ( Lloyd 2002) and the dynamic management of a company's image is seen through the eyes of its contacts and prospective hires (Martin and Beaumont 2003).

(Ambler and Barrow, 1996) first defined the term "Employer Brand" in the Journal of Brand Management in December 1996. This paper tried to associate the application of brand management techniques in the area of HRM. On that paper, Simon and Ambler defined employer brand as: the package of functional, economic and psychological benefits provided by employment opportunity, and identified with the employing organization. By 2001, the Conference Board in North America surveyed 138 leading companies and 40\% of them claimed to be actively engaged in some form of employer branding activities (Dell and Ainspan, 2001). In 2003, Economist conducted an employer brand survey among a global panel of readers which revealed a $61 \%$ level of awareness on the term 'employer branding' among HR professionals and $41 \%$ among non-HR professionals (The Economist, 2003). The first book on this subject was published back in 2005 by Barrow, S. and Mosley, R. and the second one in 2006 by Minchington, B. In 2008, Jackie Orme, the Director General of the UK Chartered Institute of Personnel stated that when he started out in the profession, nobody talked about employer branding. Now it's absolutely integral part of a business strategy.

Attitudes are the important component of marketing because of an association among attitudes, intentions and behavior. Hawkins, Best and Coney (1989), for example, claimed that "Because of 
its importance, attitudes are the central point for a considerable number of marketing strategies". Loudon and Della Bitta (1993) stated that Attitudes have been directly related to behavioral change which is a function of change in behavioral intentions. From the definition of consumer based attitude, the object of attitude is broadly interpreted. The object can be a physical thing or an action. However it is possible to relate attitude with an object (a person) or a entire group which can be a social class. Attitude portrays the relationship between a consumer and an object. Solomon, Bamossy and Askegaard (2002) assessed almost everything that can have an impact on the attitude towards something as the object of attitude and found that it is rather difficult to define the object. After that Ajzen and Fishbein (1975) identified that attitude can be described as a particular evaluation of an object, which could influence a person's emotions, knowledge or behavior with considering to the object. One more feature of attitude which emphasizes that attitude is relatively permanent and reflects behavior coherently. Schiffman and Kanuk (2004) stated that attitude can be enduring if consumer behavior is matched with consumer attitude. Attitude can be favorable or unfavorable. This feature means that attitudes can be positive or negative. According to positive and negative attitude, consumers can be sub-divided into two opposite groups. However indifference shows that attitude is neutral (Engel and Blackwell, 1998).

(Hawkins DI; Best, R J \& Coney, K A, 1989) defined attitude intensity as a reliability level of an opinion about an entity. Consumers are extremely sure of one attitudes and weakly sure of other. An attitude is steadier when it is marked by a bigger conviction. The extent and intensity of attitude might be regarded as one feature because of their relationship which means that they are not synonyms. Consumer attitudes consist of consumer's beliefs, feelings, and behavioral intentions toward some object within the context of marketing application, usually a brand or retail store. Since they are highly inter-reliant and jointly represent forces that influence how a consumer will react towards an object, therefore these components are viewed together.

In research article "Factors Associated with Students' Intentions to Engage in Science Learning Activities" by Malcolm B. Butler in 1997, he explained that the determinants of five intentions that is fourth, fifth, sixth, seventh, and eighth graders' intentions to perform science learning activities were investigated. Ajzen and Fishbein's reasoned action theory was used to assess students (sample $\mathrm{n}$ is 254) on their laboratory and non-laboratory behavioral intentions, which required using the two determinants included in the theory as well as five external variables. The five external variables consist of gender, grade, race, socioeconomic status which was determined by the range of the family's annual income, and attitude toward science. For laboratory learning activities, the two determinants were found to contribute collectively to the prediction of behavioral intention, accounting for almost a fourth of the variance. For non laboratory learning activities, two determinants accounted for over one fourth of the variance in behavioral intention. This study was run to find out the answer four research questions. First, do attitude toward behavior significantly predict behavioral intentions? Second, what is the relative impact of attitude toward behavior on students' intentions to engage in scientific learning behaviors? Third, does the prediction of behavioral intentions from attitude toward behavior and subjective norm differ when outside demographic variables, or attitude toward science are taken into consideration? And finally, what is the probable impact of these external variables on the predictors of behavioral intentions? The results identified possible external variables that should be considered in model testing application.

In article "Marketing Underground: An Investigation of Fishbein's Behavioral Intention Model" by David E. Weddle and James R. Bettman, explored the construction of attitude and the problem 
of the relationship between attitude and behavior in great intensity. They identified that in the model objects are conceptualized as having many attributes. With the help of expectancy-value approach method the attitude toward an object or action is then modeled. For each attribute or outcome, the probability that it is linked with the object or action is assessed, as is its value. The value and likelihood are then multiplied for each attribute and these products are summed. They studied different types of the model in this research article. The purpose of this paper was:

$>$ To present an initial application in the area of marketing of the Fishbein

$>$ To re-explored the controversies over the appropriate form for multiattribute models.

$>$ To examine problems in selecting appropriate attributes to describe the situation under consideration.

They used the different forms of Fishbein Model to explain the behavior and attitude of the undergraduate students. They found that these models can explain the situations better.

In a research "Cross-Cultural Examination of the Fishbein Behavioral Intentions Model" by Chol Lee and Robert T. Green (1991), explained that most of the researches regarding Fishbein's Model were tested in the United States. Consumer researchers posed some questions which concerns the applicability of these theories outside of the US. In this study they reported a crosscultural assessment of the applicability of the Fishbein behavioral intentions model in Korea and the US. Korea can be classified as a collectivist culture that is different from the individualist culture which is dominant in the US. The findings of the study recommended that the Fishbein model can be employed to explain consumers' behavioral intentions formation in a Confucian culture, as well as in the United States.

\section{Data Analysis and Interpretation:}

Table 01: Weights of importance of the attributes. (From most important to least important)

\begin{tabular}{|c|l|c|c|}
\hline SL No. & Factors & Total & Average \\
\hline 1 & Performance based promotion system & 447 & 4.47 \\
\hline 2 & Remuneration & 446 & 4.46 \\
\hline 3 & Growth opportunity & 444 & 4.44 \\
\hline 4 & Social status & 433 & 4.33 \\
\hline 5 & Job security & 422 & 4.22 \\
\hline 6 & Brand image & 420 & 4.2 \\
\hline 7 & Learning environment & 413 & 4.13 \\
\hline 8 & General and study leave & 409 & 4.09 \\
\hline 9 & Organizational corporate culture & 399 & 3.99 \\
\hline 10 & Opportunity of loan facility & 377 & 3.77 \\
\hline 11 & Reward and incentive & 368 & 3.68 \\
\hline 12 & Opportunity of foreign visit & 352 & 3.52 \\
\hline
\end{tabular}


International Journal of Managing Value and Supply Chains (IJMVSC) Vol.4, No. 4, December 2013

\begin{tabular}{|c|l|c|c|}
\hline 13 & Workload & 351 & 3.51 \\
\hline 14 & Scope of being honest & 341 & 3.41 \\
\hline 15 & Retirement and pension benefit & 320 & 3.2 \\
\hline 16 & $\begin{array}{l}\text { Role in decision making and scope } \\
\text { for new ideas }\end{array}$ & 307 & 3.07 \\
\hline 17 & $\begin{array}{l}\text { Fellow workers performance and } \\
\text { team environment }\end{array}$ & 301 & 3.01 \\
\hline 18 & Opportunity for helping people & 291 & 2.91 \\
\hline 19 & Physical set up & 273 & 2.73 \\
\hline 20 & Housing facility & 268 & 2.68 \\
\hline 21 & Seniority based promotion system & 257 & 2.57 \\
\hline
\end{tabular}

\section{Source- Primary survey}

Followings are the individual attribute analysis:

Overall Attitude of the Business Students towards the career in BB, PCBs \& NCBs

Figure 1: Attitude of business students towards the career in BB, PCB, \& NCBs (Average of $\sum$ $\mathrm{EiBi})$

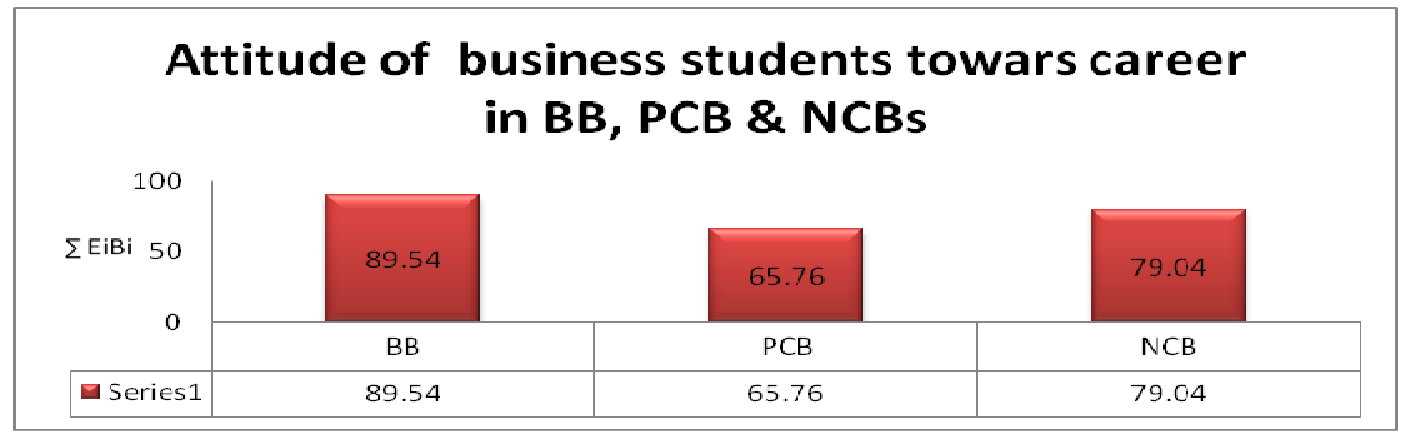

Observation: from the overall analysis of the study we can see that student's attitude towards the career in central bank (89.54) is higher in contrast with PCBs (65.76) \& NCBs (79.04).

Factor wise Observation:

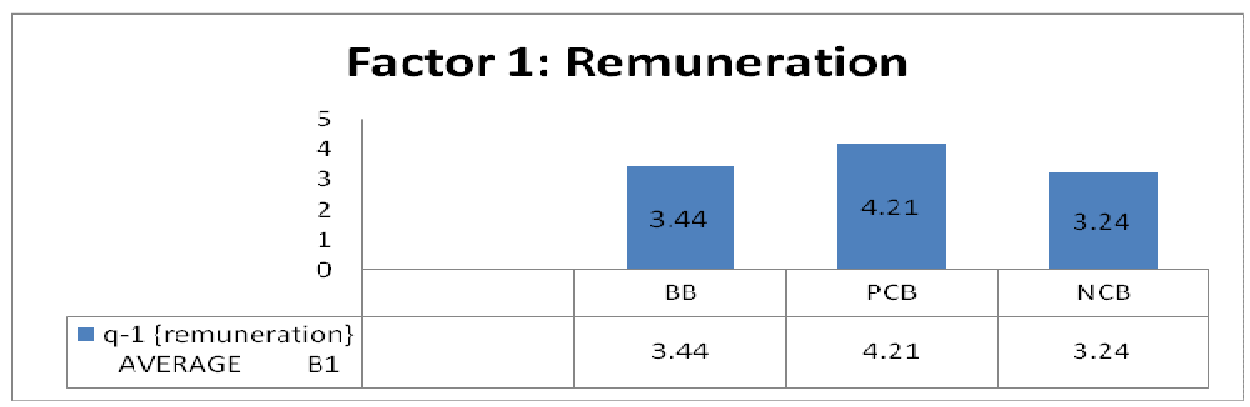


International Journal of Managing Value and Supply Chains (IJMVSC) Vol.4, No. 4, December 2013
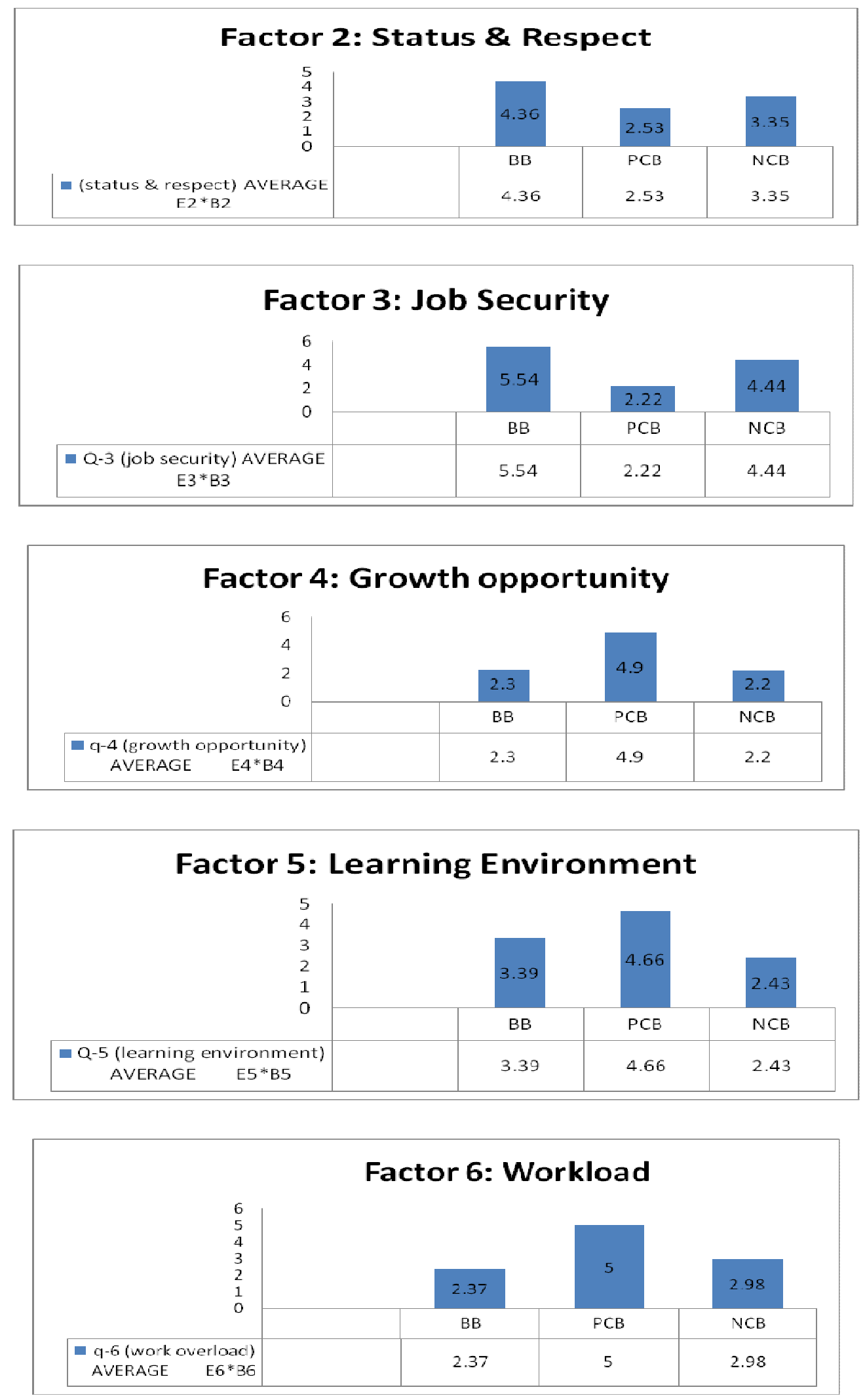
International Journal of Managing Value and Supply Chains (IJMVSC) Vol.4, No. 4, December 2013

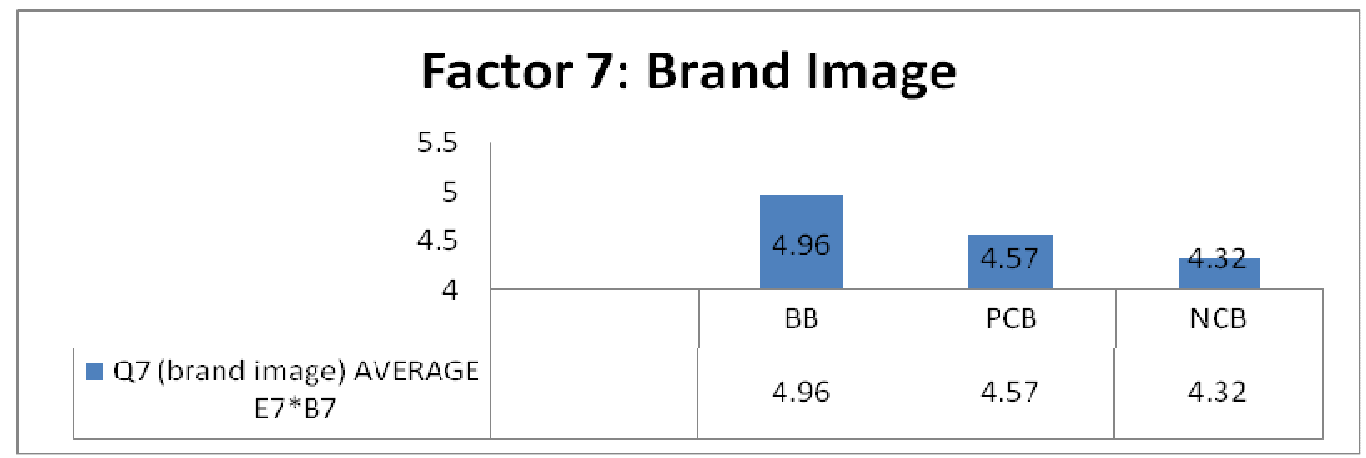

\section{Factor 8: General and Study Leave}

Q8 (general and study leave) AVERAGE $\mathrm{E} 8 * \mathrm{~B} 8$

\begin{tabular}{c|}
6 \\
4 \\
2 \\
0
\end{tabular}

\section{Factor 9: Opportunity of Foreign Visit}

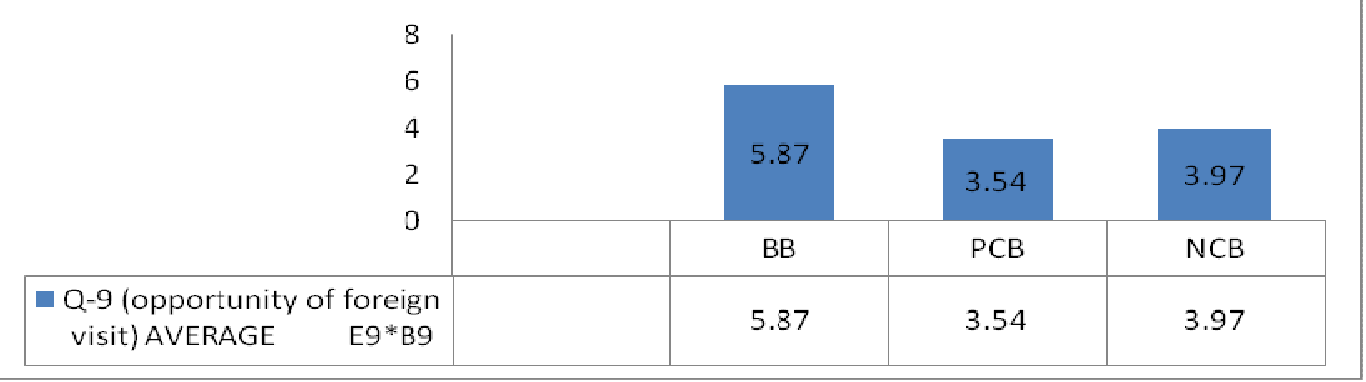

\section{Factor 10: Loan Facilities}

\begin{tabular}{|c|c|c|c|}
\hline \multirow[t]{2}{*}{$\begin{array}{l}8 \\
6 \\
4 \\
2 \\
0\end{array}$} & 5.76 & 2.54 & 5.43 \\
\hline & BB & PCB & $\mathrm{NCB}$ \\
\hline $\begin{array}{c}\text { Q10 (opportunity of loan } \\
\text { facilities) AVERAGE } \\
\text { E10*B10 }\end{array}$ & 5.76 & 2.54 & 5.43 \\
\hline
\end{tabular}


International Journal of Managing Value and Supply Chains (IJMVSC) Vol.4, No. 4, December 2013
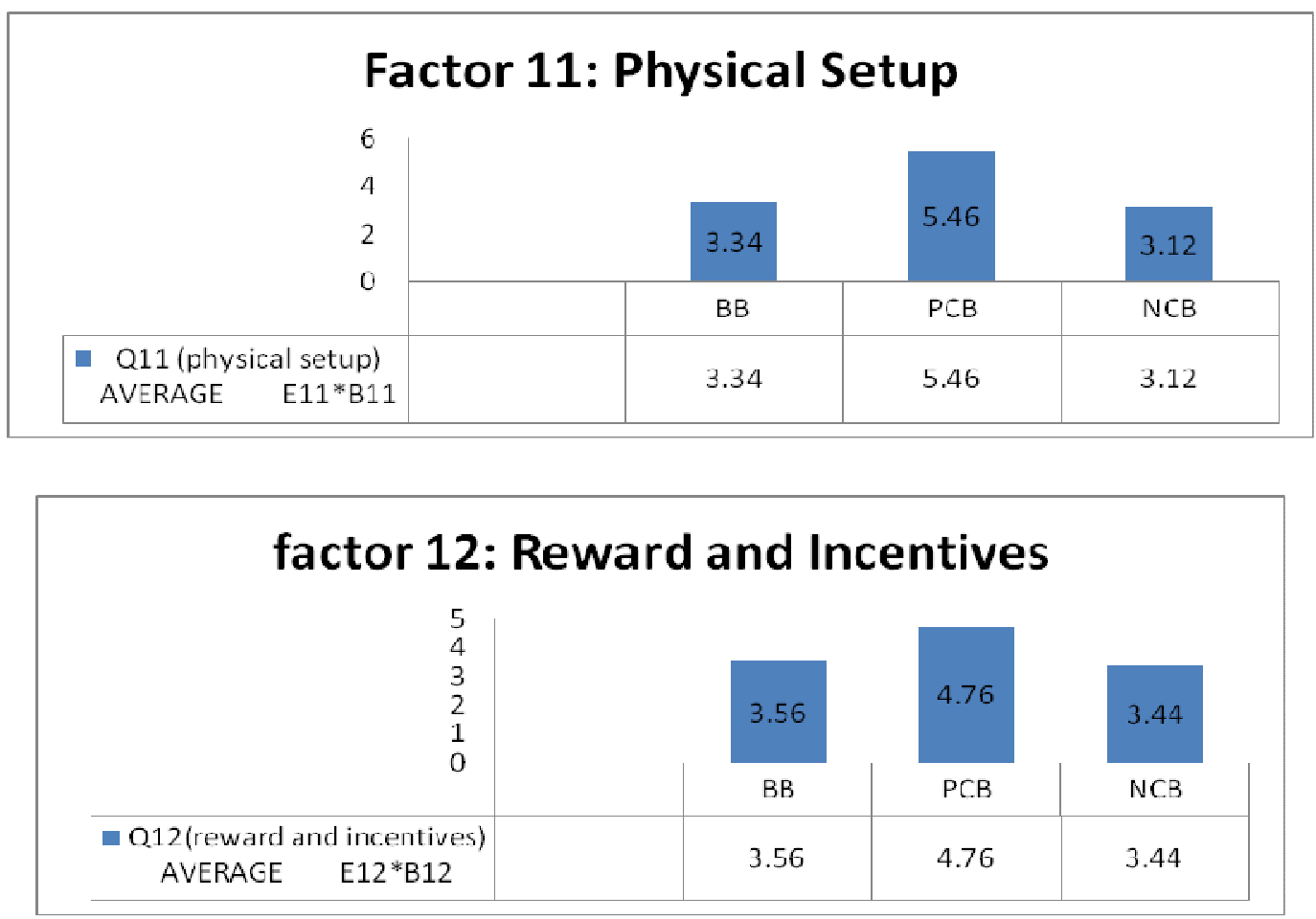

Factor 13: Performence Based Promotion

Q13(performence based promotion system) AVERAGE

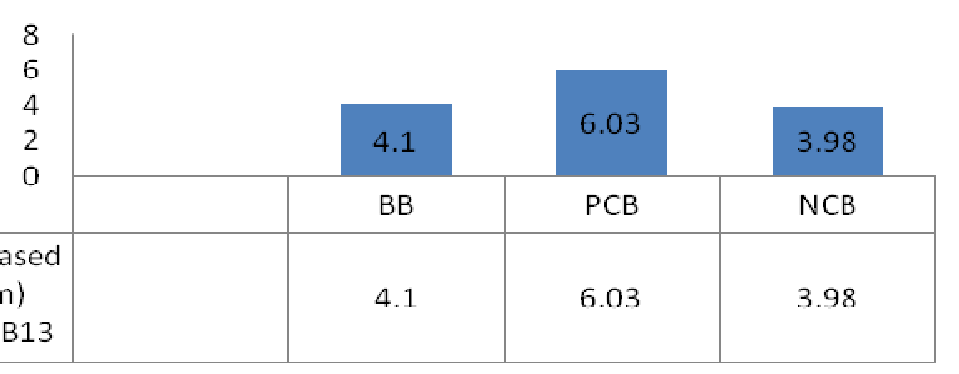

\section{Factor 14: Seniority Based Promotion}

\begin{tabular}{|c|c|c|c|}
\hline \multirow[t]{2}{*}{$\begin{array}{l}6 \\
4 \\
2 \\
0\end{array}$} & 5 & 2.76 & 4.54 \\
\hline & BB & PCB & $\mathrm{NCB}$ \\
\hline $\begin{array}{c}\text { Q14(seniority based } \\
\text { promotion system) AVERAGE } \\
\text { E14*B14 }\end{array}$ & 5 & 2.76 & 4.54 \\
\hline
\end{tabular}



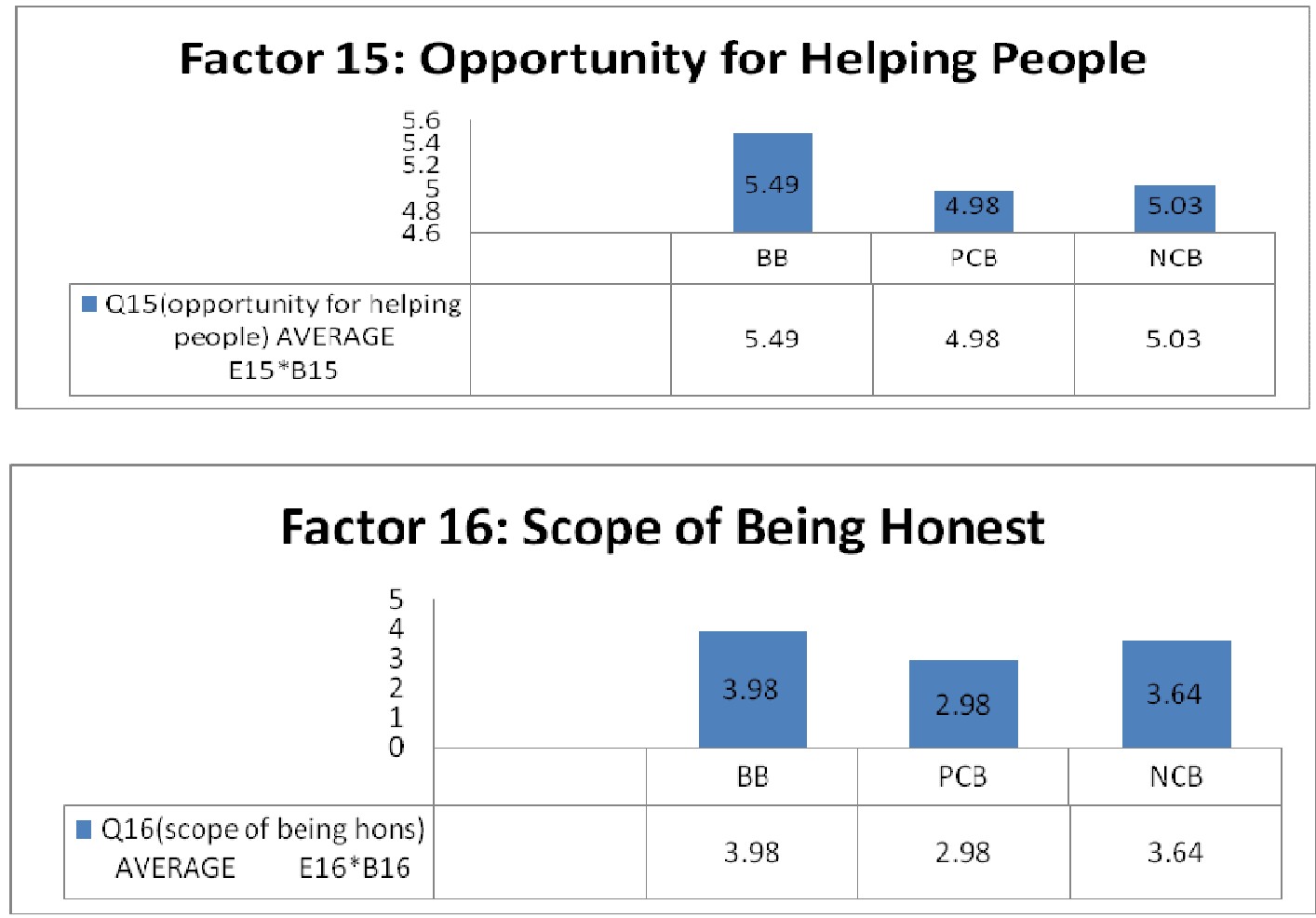

Factor 17: Role in Decision Making and Scope for New Ideas

Q17(role in decision making and scope for new ideas) AVERAGE
6
4
2
0 $\mathrm{E} 17 * \mathrm{~B} 17$

Factor 18: Fellow Workers' Performance and Team Environment

Q18(fellow workers' performance and team environment) AVERAGE E18*B18

\subsection{7 \\ BB \\ 3.87}

4.98

3.16
3.16

NCB

PCB

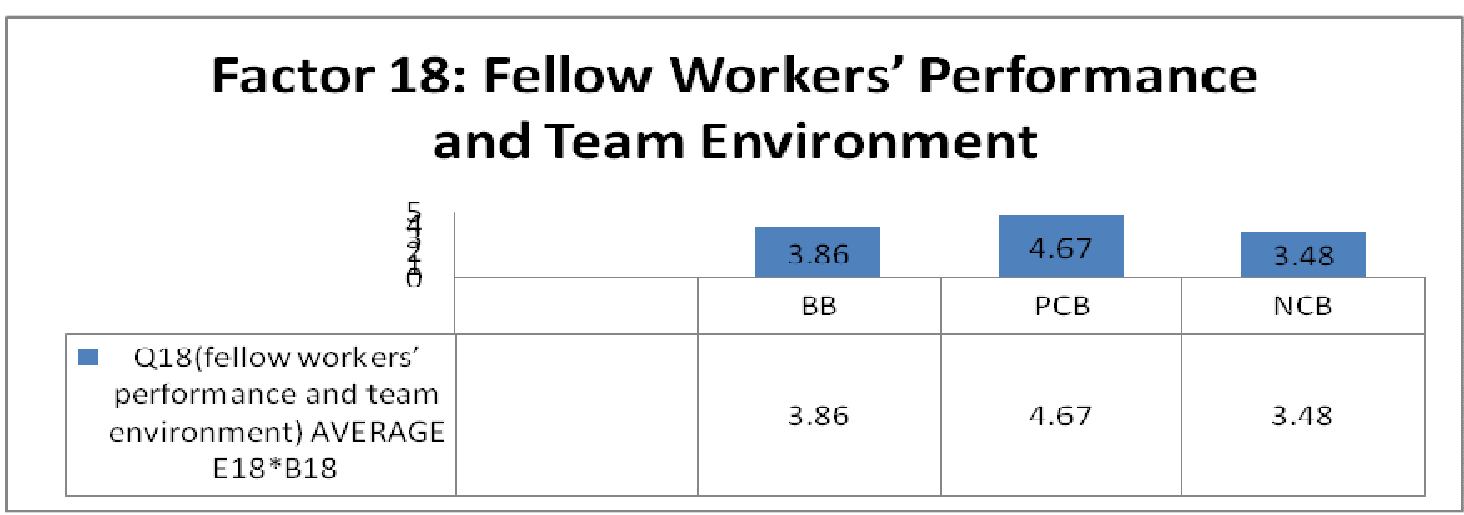



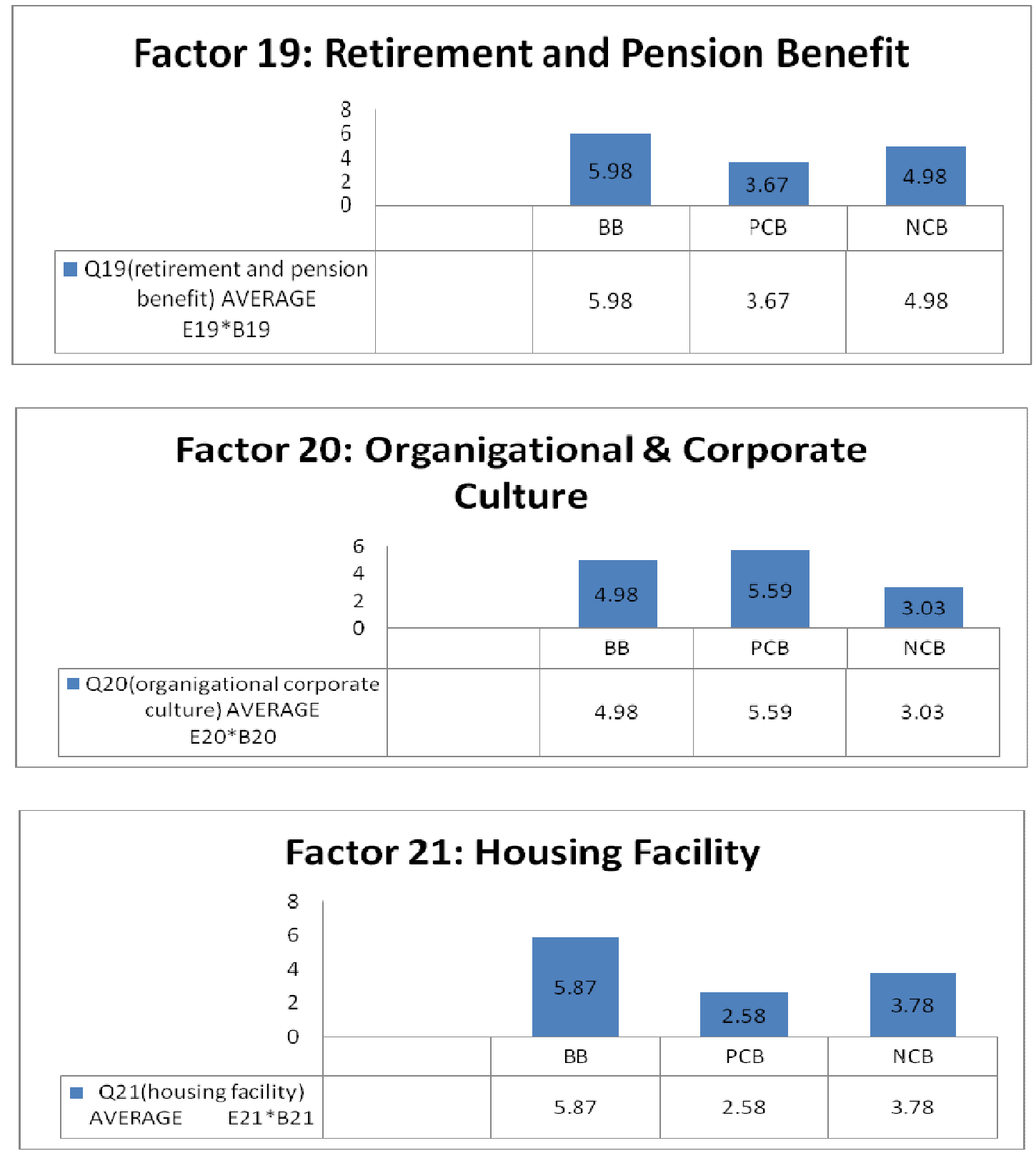

\section{Findings}

After analyzing the survey, these results were found. The general findings are as follows:

* Taken as a whole, the analysis of the data has found that students have more positive attitude towards the career of Private commercial bank followed by Bangladesh bank \& nationalized commercial banks. The interesting thing is that, negative attitude is found about the career in NCBs. 
International Journal of Managing Value and Supply Chains (IJMVSC) Vol.4, No. 4, December 2013

* According to the study, Performance based promotion system (4.47) is found to be the most important attribute, followed by, Remuneration (4.46), Growth opportunity (4.44), Social status (4.33), Job security (4.22) \& Brand image (4.2).

* According to the study PCBs secured the best position in Remuneration, growth opportunity, learning environment, brand image, opportunity to foreign visit, Physical setup, rewards \& incentives, performance based promotion system, scope of being honest, role in decision making \& scope for new ideas, fellow workers' performance \& team environment and corporate culture.

* According to the study BB secured the best position in status \& respect, job security, general \& study leave, retirement \& pension benefit and housing facility.

* According to the study NCBs secured the best position in workload, loan facility and seniority based promotion system.

* From the analysis of the tables and figures we have found that students have negative attitude on nationalized commercial banks on most of the attributes.

* Students have more positive attitude towards Private commercial banks.

\section{Conclusion:}

The objective of the study was to find out the attitude of business students. From here we can have some clear understanding about what students think most important for a banking career and what these banks are providing them with. Employer branding has been a very popular concept in recent times. Different industries are trying to attract the best pool of candidates for their jobs. Not only attracting the right talent but also retaining them becomes a critical aspect for business success. A "brand employer" can easily retain as the good brand gives them the edge. Underneath of this positioning is that your brand as an employer aids as a talent self-selection tool. The Bangladeshi banking industry is a very big employer Thousands of graduates from business and non-business background is trying to get a job in this industry. The salary and other incentives provided by the banking jobs is the highest compared to any other industry in Bangladesh. But the industry is facing some serious problems to retain those talents. Root of some problems is very deep inside the organization and management setup. But one of the most obvious one is certainly their brand as employers. Some of the private banks are really trying their best. On the other hand government banks are considered as good brands compared to the private ones in terms of many other aspects except salary. The problems in the government owned banking sector is the salary and other incentives. The government has addressed this issue and trying to increase the salary. But unlike the private commercial banks it faces big hurdles like pressure from bureaucrats (as they will be getting lower salaries than bankers and they can't simply accept this fact). But nonetheless the banking sector is still emerging and employing many of the best graduates of this country. 
International Journal of Managing Value and Supply Chains (IJMVSC) Vol.4, No. 4, December 2013

\section{References:}

- Ambler, T and Barrow, S. (1996), The employer brand, "The Journal of Brand Management", Vol. 4, pp185-206.

- Barrow, S. and Mosley, R. The Employer Brand, Bringing the Best of Brand Management to People at Work, John Wiley \& Sons, Chichester.

- David E. Weddle and James R. Bettman (1974),"Marketing Underground: an Investigation of Fishbein's Behavioral Intention Model", in NA - Advances in Consumer Research Volume 01, eds. Scott Ward and Peter Wright, Ann Abor, MI : "Association for Consumer Research", Pages: 310-318.

- Dell, D and Ainspan, N (2001), Engaging employees through your brand, Conference Board Report No. R-1288-01-RR, April, Conference Board, Washington, D.C.

- Engel, J.F. Consumer Behavior / J.F. Engel, R.D. Blackwell, P.W. Miniard, Dryden, 1998, pp 789.

- Fishbein, M. and Ajzen, I. (1975), Belief, Attitude, Intention and Behavior: An Introduction to Theory and Research, Addison-Wesley, Reading, MA.

- Hartman \& Dean Devere (1972). "The determination of applicability of the Fishbein Model of Attitudes in Ascertaining the Attitudes Toward Science Held by the High School Students", 1972. Pp 154.

- Hawkins DI; Best, R J \& Coney, K A (1989). Consumer Behavior: Implications For Marketing Strategy. Homewood, Boston: BPI/IRWIN. P-433

- Lee, Chol, \& Robert T. Green. 1991, "crosscultural examination of the Fishbein behavioral intentions model", "Journal of International Business Studies", 22, no. 2: 289-306

- Lloyd, S (2002), 'Branding from the inside out', "Business Review Weekly", Vol 24 No 10, pp6466.

- Loudon DL \& Della Bitta AJ (1993). Consumer Behavior: Concepts and Applications (4thed). McGraw Hill: Auckland.

- Martin, G. and Beaumont, P. (2003), Branding and People Management, CIPD Research Report, CIPD, London.

- Minchington, B (2010) Employer Brand Leadership - A Global Perspective, Collective Learning Australia.

- Mitchell, C. (2002), 'Selling the brand inside', "Harvard Business Review”, Vol.80, No.1, pp99105.

- Mosley, R (2007) 'Customer experience, organisational culture and the employer brand', "Journal of Brand Management”, Vol 15, October Issue pp123-134.

- Papasolomou, I and Vrontis, B (2006), 'Using internal marketing to ignite the corporate brand', "Journal of Brand Management", Vol 14, Nos 1/2, pp177-195.

- Sartain, L and Schumann, M. (2006), Brand from the Inside, John Wiley \& Sons, San Francisco.

- Schiffman, L.G. Consumer Behavior / L.G. Schiffman, L.L. Kanuk. Prentice Hall, 2004, p. 250287

- Solomon, M. Consumer Behaviour. A Europien Perspective /M. Solomon, G. Bamossy, S. Askegaard. Prentice Hall, 2002, p.126-153. 